\title{
Acute Phenylalanine/Tyrosine Depletion Reduces Motivation to Smoke Cigarettes Across Stages of Addiction
}

\author{
Viswanath V Venugopalan', Kevin F Casey', Caitlin O'Hara², Jennifer O'Loughlin ${ }^{3}$, Chawki Benkelfat ${ }^{1,4}$, \\ Lesley K Fellows ${ }^{1,2}$ and Marco Leyton*, ${ }^{, 1,2,4}$ \\ 'Departments of Neurology and Neurosurgery, McGill University, Montreal, QC, Canada; ${ }^{2}$ Department of Psychology, McGill University, \\ Montreal, QC, Canada; ${ }^{3}$ Department of Psychiatry, McGill University, Montreal, QC, Canada; ${ }^{4}$ Department of Epidemiology, \\ Université de Montréal, Montreal, QC, Canada
}

\begin{abstract}
The neurobiology of tobacco use is poorly understood, possibly in part because the relevant mechanisms might differ depending on past nicotine exposure and degree of addiction. In the present study we investigated whether these factors might affect the role of dopamine (DA). Using the acute phenylalanine/tyrosine depletion method (APTD), DA synthesis was transiently decreased in three groups of abstinent smokers $(n=47)$ : ( 1 ) early low-frequency smokers, who had smoked a maximum of five cigarettes per day for less than one year, (2) stable low-frequency smokers smoking at the same level as early low-frequency smokers for at least 3 years, and (3) stable high-frequency smokers, who smoked a minimum of 10 or more cigarettes per day for at least 5 years. Motivation to obtain tobacco was measured using a progressive ratio breakpoint schedule for nicotine-containing and de-nicotinized cigarettes. Compared with a nutritionally balanced control mixture, APTD decreased the self-administration of nicotine-containing cigarettes, and this occurred in all three groups of smokers. The results suggest that DA influenced the willingness to sustain effort for nicotine reward, and this was seen in participants at all three levels of cigarette addiction. In the transition from sporadic to addicted use, the role of DA in the motivation to seek drug may change less than previously proposed.

Neuropsychopharmacology (20I I) 36, 2469-2476; doi:I0.1038/npp.20 I I.I35; published online 20 July 201 I
\end{abstract}

Keywords: dopamine; motivation; nicotine; addiction; craving; smoking

\section{INTRODUCTION}

The neurobiology of tobacco use at varying stages of addiction is not well understood. Studies in laboratory animals, however, implicate a role for nicotine-induced dopamine (DA) release (Clarke, 1990; Rose and Corrigall, 1997; Sorge and Clarke, 2009). Following acute administration, nicotine binds to nicotinic cholinoceptors on DA cell bodies in the ventral tegmental area of the midbrain (Clarke et al, 1988) and elicits DA release in the ventral striatum (Di Chiara and Imperato, 1988). Repeated nicotine exposure can lead to progressive increases in its rewarding and behaviorally activating effects (Vezina et al, 2007). For example, initial intermittent exposures to nicotine (three to six times) result in progressively greater effects on locomotor activity (Clarke and Kumar, 1983; Louis and Clarke, 1998), enhance the acquisition of self-administration (Shoaib et al, 1997), increase conditioned place

*Correspondence: Dr Marco Leyton, Department of Psychiatry, McGill University, 1033 Pine Avenue West, Montreal, Quebec, Canada H3A |Al. Tel: + | 5 |4 398 5804, Fax: + | 5 |4 398 4866,

E-mail: marco.leyton@mcgill.ca

Received I4 March 20 I ; revised 6 June 20 I I; accepted I6 June 20 I I preferences (Shoaib et al, 1994), and precipitate greater DA overflow in the nucleus accumbens (Balfour et al, 1998; Benwell and Balfour, 1992; Domino and Tsukada, 2009; Shim et al, 2001). Preventing this DA response disrupts nicotine self-administration and nicotine-relatedconditioned place preferences (Corrigall and Coen, 1991; Liu et al, 2010; Shoaib et al, 1994; Sorge and Clarke, 2009; Spina et al, 2006; Tang and Dani, 2009). The contribution of DA following more extensive nicotine exposure, though, remains largely unexplored.

Attempts to translate these findings to humans have been equivocal. Functional neuroimaging studies have demonstrated DA release in response to cigarette smoking (Barrett et al, 2004; Brody, 2006; Brody et al, 2004; Scott et al, 2007), but attempts to alter smoking behavior by decreasing DA transmission have provided contradictory results. In these studies, smoking patterns were seen to increase (Caskey et al, 1999; Caskey et al, 2002; Dawe et al, 1995; Hitsman et al, 2008), decrease (Brauer et al, 2001), and remain unchanged (Casey et al, 2006; Hutchison et al, 2004). This variability might reflect differences in nicotine self-administration paradigms, the use of nonspecific DA receptor antagonists, or a change in the role of DA, as smokers transition from occasional to dependent cigarette use. 
In the present study, we investigated the effect of decreasing DA transmission on the motivation to smoke and self-reports of cigarette pleasure and craving at three different stages of tobacco addiction: (1) low-frequency early smokers (LFES), who have smoked less than 1 year and smoke no more than five cigarettes per day and not every day, (2) low-frequency stable smokers (LFSS), who have smoked for at least 3 years, smoking no more than five cigarettes a day, not necessarily every day, and (3) highfrequency stable smokers (HFSS) who have smoked for more than 5 years and smoke 10 or more cigarettes per day, every day. Motivation to obtain cigarettes was measured using a progressive ratio (PR) breakpoint paradigm adapted for humans (Barrett et al, 2006). DA transmission was decreased using the acute phenylalanine/tyrosine depletion method (APTD) (Leyton et al, 2000b).

\section{MATERIALS AND METHODS}

\section{Subjects}

Forty-seven smokers, aged from 18 to 25 years old $(20.4 \pm 2.5$ years; mean $\pm \mathrm{SD})$, were recruited from the community through advertisements placed on the McGill University classified website and in local Montreal newspapers. All subjects underwent a routine medical exam and standard blood work, and were deemed fit to participate by a physician. All subjects were evaluated using the semistructured clinical interview using DSM-IV criteria (First, 1995). This study was approved by the Research Ethics Board of the Royal Victoria Hospital, McGill University Health Center. Written, informed consent was obtained from all participants. All participants were free of all current Axis I disorders, including major depressive disorder, bipolar disorder, psychosis, psychoactive substance use disorder, excluding nicotine and caffeine, panic disorder, generalized anxiety disorder, and obsessive compulsive disorder.

\section{Group Assignment}

Subjects who met our eligibility criteria were divided into HFSS, LFSS, and LFES groups, based on cigarettes smoked per day, number of years smoking, and on the degree of nicotine dependence as determined by the Fagerström test for nicotine dependence (FTND) (Fagerstrom, 1978; Fagerstrom and Schneider, 1989; Heatherton et al, 1991) and the hooked on nicotine checklist (HONC) (DiFranza et al, 2002). HFSS had a combined FTND and HONC score of 10 or higher. Both groups of low-frequency smokers had a combined score of 9 or less.

\section{Study Design}

Two test sessions were conducted at minimum of 3 days apart. On the morning of each test day, subjects ingested a drink deficient in phenylalanine and tyrosine (APTD), or a nutritionally balanced control mixture (BAL). The order of conditions was randomly assigned and counterbalanced across groups. Both subjects and experimenters were blind to condition. The composition, preparation, and administration of the APTD mixture were based on a balanced amino acid (AA) mixture, with phenylalanine and tyrosine withheld (Leyton et al, 2000b). The AA mixtures were adapted for women by reducing the amount of protein by $17 \%$ to account for lower body weight. On the day before testing, subjects ate a low-protein diet supplied by the investigators. They were asked to refrain from alcohol use on this day and to restrict themselves to three caffeinated drinks. Subjects were asked to fast and remain abstinent from cigarettes from midnight before the test session.

On test days, subjects arrived at the laboratory at $0930 \mathrm{~h}$. At this time, they provided a urine sample, which was tested for drugs (Triage Panel for Drugs of Abuse, sensitive to cocaine, amphetamines, barbiturates, benzodiazepines, $\Delta^{9}$-tetrahydrocanabinol, opiates, and phencyclidine; Biosite Diagnostics, San Diego, CA, USA). They also provided a breath carbon monoxide measure (cutoff for abstinence $<10$ p.p.m., Vitalograph-Breath CO Monitor) to confirm smoking abstinence. All female participants were given a urine pregnancy screen and were tested while in the follicular phase of their menstrual cycle. Subjects who tested positive for any drug, or had carbon monoxide levels in excess of 10 p.p.m. on a testing day were not tested on that date. Following confirmation of a negative toxicology and pregnancy screening, blood samples were then drawn to assess baseline plasma AA levels. All samples were immediately centrifuged and the plasma was fractioned-off and stored at $-80^{\circ} \mathrm{C}$ until analysis. Following the baseline blood sample draw and the administration of self-report scales, subjects were asked to ingest the AA mixture. Four hours following ingesting of the AA mixture, a second blood draw was performed to assess any changes in plasma AA levels compared with baseline.

\section{Plasma Amino Acids}

Plasma concentrations of phenylalanine, tyrosine, and other large neutral AAs (LNAAs) were measured by HPLC with precolumn derivatization and fluorometric detection. Plasma samples were missing from 3 of the 94 test days.

\section{Subjective States}

Subjects were administered 14 visual analog scales (VAS) at three time points over the course of the test day: immediately before ingesting the AA mixture, $4 \mathrm{~h}$ after ingesting the AA mixture, and at the end of the test session. The items were: alert, anxious, bored, edgy, energetic, euphoria, excited, hungry, intend to smoke, interested, like cigarette, mind-racing, rush, and want cigarette. Items were rated on a $10-\mathrm{cm}$ line labeled with the integers $1-10$ and anchored with the words 'least' and 'most'. Subjective cigarette craving was measured with the questionnaire on smoking urges (QSU) (Tiffany and Drobes, 1991); administered at the same time points as the VAS. This self-report measure yields a total craving score, and scores for two factors ranging from 1 to 7 , with 4 representing a neutral midpoint. The total score represents overall instantaneous cigarette craving. Factor 1 measure aspects of smoking related to positive affect such as the pleasantness or satisfaction derived from smoking a cigarette. Factor 2 emphasizes craving for cigarettes to relieve withdrawal or negative emotions related to cigarettes. Clinical and 
sub-clinical changes in mood state were measured with the Beck depression inventory (BDI) (Beck, 1961) and the bipolar profile of mood states (POMS) (Lorr et al, 1982), each of which was administered at the beginning and end of the test days.

\section{Cue-Induced Cigarette Craving}

Before each cigarette self-administration session, participants were comfortably seated in a chair in front of a computer. Participants were instructed to handle a neutral cue (ie, a pen) and following that to complete VAS and QSU scales. Participants were then instructed to hold a cigarette (lit by the experimenter) for $1 \mathrm{~min}$, but were not allowed to smoke the cigarette for $1 \mathrm{~min}$. Again participants were asked to complete VAS and QSU scales after having held the lit cigarette.

\section{Cigarette Self-Administration Task}

Four hours following AA ingestion, participants were offered the opportunity to earn up to 10 mini-cigarettes (one-tenth of a regular sized cigarette) on a PR schedule, an objective behavioral measure of the motivation to smoke. This time point was chosen to coincide with peak biochemical and behavioral effects observed in previous APTD studies (Leyton et al, 2005; Leyton et al, 2004). Participants had the choice to earn and smoke nicotinecontaining cigarettes $(0.6 \mathrm{mg} /$ entire cigarette) or de-nicotinized Quest 1 tobacco cigarettes (Vector Tobacco, USA). Before the task, however, subjects were informed only that they could earn mini-cigarettes from two different cigarette brands. To earn each mini-cigarette, participants were required to repeatedly press the letters ' $w$ ' and ' $a$ ' for a predetermined number of times to earn a nicotine-containing cigarette, whereas de-nicotinized cigarettes were similarly earned using the letters ' $\mathrm{d}$ ' and ' $r$ '. Participants were blind to the outcome of the key presses, that is, which key press combination would earn nicotine-containing or denicotinized mini-cigarettes. For each type of cigarette, the first earned mini-cigarette required 50 button presses and the number of presses required to earn each subsequent mini-cigarette of either type doubled (PR ratio: 50, 100, 200, $400,800,1600,3200,6400,12800$, and 25600 ). Each session lasted until the maximum number of mini-cigarettes was earned or to a maximum of $2 \mathrm{~h}$, whichever came first. Participants were not required to earn mini-cigarettes during the sessions, but were required to remain seated in the testing room until each session was completed.
Upon completion of the self-administration task, participants were brought a meal and then sent home by taxi and were paid at the end of the experiment.

\section{Statistical Methods}

All data were analyzed using Statview, version 5.0.1. The primary outcome variables in this study were the number of button presses during the PR task to earn mini-cigarettes in each AA session. The PR (button press) data were log-transformed to permit parametric analyses. These data were then analyzed using a $2 \times 2 \times 3$ repeated measures ANOVA using AA condition (BAL, APTD) and cigarette type (nicotine-containing and de-nicotinized) as within-subject factors and group (LFES, LFSS, and HFSS) as betweensubject factor. Familywise Bonferroni corrections were applied when related analyses were conducted on several variables. Analyses of the VAS and QSU data were subjected to repeated measures ANOVAs, with AA mixture (BAL, APTD), and Time (pre-session, $t+4$, and post-session) as within subject factors and group (LFES, LFSS, HFSS) as between-subject factor. VAS and QSU data following cue exposure were analyzed using $2 \times 2 \times 3$ repeated measures ANOVA with cue (neutral, cigarette) and AA mixture (BAL, APTD) as within-subject factors and group (LFES, LFSS, HFSS) as a between-subject factor.

\section{RESULTS}

\section{Participants}

Forty-seven participants completed the study protocol. Four additional participants discontinued following their first AA session; three withdrew because of nausea following ingestion of the AA mixture, while the fourth did not complete the study because of relocation.

As expected, the three groups differed significantly on variables related to their level of tobacco use. The three groups did not differ, though, on demographic features, including age, sex, gender, and education. LFES consumed significantly more alcoholic drinks per week than HFSS $[\mathrm{F}(2,45)=3.7, p=0.04]$ (Table 1$)$.

\section{Amino Acid Depletion}

On the APTD test session, plasma concentrations of tyrosine and phenylalanine decreased significantly, as reflected by AA Mixture $\times$ Time interactions: tyrosine $\mathrm{F}(2,1)=$ $228.3 p<0.0001$; phenylalanine $\mathrm{F}(2,1)=203.74 p<0.0001$.

Table I Subject Characteristics

\begin{tabular}{|c|c|c|c|c|c|c|c|c|}
\hline Group & $\mathbf{N}$ & Age (years) & $\operatorname{Sex}(M / F)$ & Education (years) & FTND & HONC & Cigarettes/day & Drinks/week \\
\hline HFSS & 16 & $21.0(1.8)$ & $10 / 6$ & $14.4(1.5)$ & $5.3(1.4)^{* * * *}$ & $8.4(1.2) * * *$ & 12.6(4.4)**** & 6.1 (4.8)* \\
\hline LFSS & 16 & $21.8(2.4)$ & $6 / 10$ & $15.0(1.0)$ & $3.1(1.5)$ & $5.0(1.9)^{* *}$ & $4.9(3.2)$ & $8.9(7.0)$ \\
\hline
\end{tabular}

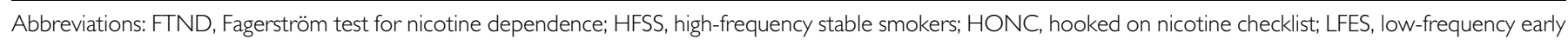
smokers; LFSS, low-frequency stable smokers. See text for details. Mean given with SD in parentheses.

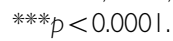

*** $p<0.005$.

$*_{p}<0.05$ (in comparison with LFES) 
Four hours after ingesting the mixture, the APTD treatment decreased tyrosine and phenylalanine levels to $22.9 \%$ and $15.1 \%$, respectively, of morning baseline levels, whereas the BAL mixture increased plasma tyrosine and phenylalanine levels by $240 \%$ and $236 \%$, respectively. Ingestion of both Mixtures also significantly decreased the ratios of plasma tyrosine and phenylalanine to other LNAA (tyrosine, phenylalanine, tryptophan, leucine, isoleucine, valine, and methionine $)(p<0.001)$. However, AA Mixture $\times$ Time interactions revealed that these reductions were significantly more pronounced in the APTD relative to the BAL condition: tyrosine $(94.8 \%$ vs $32.5 \%), \mathrm{F}(2,1)=35.2$, $p<0.0001$; phenylalanine (96\% vs 33.7\%), $\mathrm{F}(2,1)=66.1$, $p<0.0001$ (Table 2).

\section{Cigarette Self-Administration Progressive Ratio Breakpoints}

As depicted in Figure 1, all three groups worked more for nicotine-containing cigarettes than for de-nicotinized ones $[\mathrm{F}(1,39)=84.4, \quad p<0.0001] . \quad$ A Group $\times$ Cigarette-type interaction $[\mathrm{F}(2,39)=6.3, p<0.01]$ indicated that highfrequency smokers worked more than low-frequency smokers for nicotine-containing mini-cigarettes $(p<0.01)$ but not for de-nicotinized ones $(p=0.43)$. Finally, APTD, compared with BAL, decreased the number of mini-cigarettes worked for by all three groups of smokers $[\mathrm{F}(1,39)=4.4, p<0.05)]$, and this effect was the same in all three groups as indicated by the absence of Group $\times$ AA Mixture $[\mathrm{F}(1,39)=0.52, p=0.59]$ and Group $\times$ Cigarettetype $\times$ AA Mixture interactions $[\mathrm{F}(2,39)=0.86, p=0.43]$. The AA Mixture $\times$ Cigarette-type interaction was not significant $[\mathrm{F}(1,39)=0.99, p=0.32]$, but inspection of the data suggested that the main effect of APTD was primarily driven by decreased self-administration of the nicotinecontaining cigarettes $(p<0.05)$, but not denicotinized ones $(p=0.50)$.

\section{Effects Of APTD And Time On VAS Scores}

Repeated measures ANOVA (Group $\times$ AA Mixture $\times$ Time) showed main effects of Group $[\mathrm{F}(2,39)=5.2, p<0.05]$ and Time $[\mathrm{F}(4,39)=12.3, p<0.001)]$ on ratings of VAS items Like Cigarette and Want Cigarette. Post-hoc analyses revealed that HFSS and LFSS rated Like Cigarette and Want Cigarette higher compared with LFES at all time points $(p<0.01)$
(Table 3). Following the first cigarette, ratings were significantly lower than at previous time points $(p<0.001)$.

Repeated measures ANOVA (Group $\times$ AA Mixture $\times$ Time) revealed main effects of Group $[\mathrm{F}(2,39)=4.9$, $p<0.05]$ and Time $[\mathrm{F}(4,39)=6.7, p<0.01)$ on ratings of VAS item 'Euphoria' and 'High'. Post-hoc analyses revealed that ratings of 'Euphoria' and 'High' were higher in HFSS than in LFES and LFSS $(p<0.05)$. Ratings of 'Euphoria' and 'High' were significantly different at time points 'Cig cue' and 'Post-Cig' compared with all three previous time points $(p<0.01) \quad$ (Table 3$)$. An effect of Time and Group differences was observed on several VAS items (Supplementary Table S1). However, APTD had no effect on the rating of any VAS items at different time points.

\section{The Effects Of APTD And Time On Self-Reported Craving}

Group differences on Factor 2 ratings of the QSU were observed with HFSS and LFSS scoring significantly higher than LFES $(p<0.01)$. No group differences were observed on Factor 1 ratings. Effects of AA Mixture or Cue on QSU Factor 1 and Factor 2 ratings were not observed (Table 4).

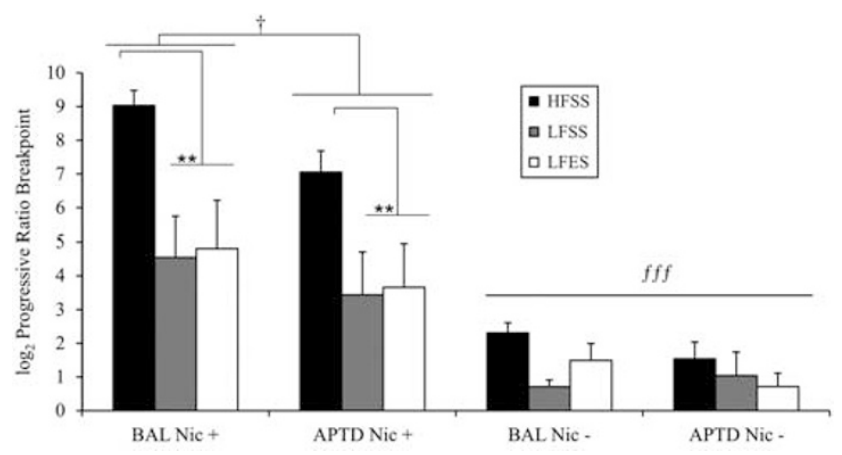

Figure I Effect of acute phenylalanine and tyrosine depletion (APTD) on progressive ratio breakpoints for nicotine-containing $(\mathrm{Nic}+)$ and de-nicotinized cigarettes (Nic -). HFSS, LFSS, and LFES refer to highfrequency stable smokers, low-frequency stable smokers, and lowfrequency early smokers, respectively. All three groups of smokers worked for more Nic + cigarettes compared with Nic - ones $(p<0.000$ I, (fff)). HFSS worked for more Nic + compared with both groups of lowfrequency smokers $(p<0.01)$, (***). In all three groups, Nic + self-administration was significantly attenuated in the APTD condition with relative to $\mathrm{BAL}(p<0.05,(\dagger))$.

Table 2 Plasma Levels of Tyrosine and Phenylalanine, and Ratios of Tyrosine and Phenylalanine to Large Neutral Amino Acids at a.m. Baseline and $4 \mathrm{~h}$ Following Amino Acid Ingestion

\begin{tabular}{|c|c|c|c|c|c|c|}
\hline Amino acid & BAL (a.m.) & BAL (p.m.) & \% Difference & APTD (a.m.) & APTD (p.m.) & \% Difference \\
\hline Tyrosine & $56.7(13.3)$ & | $36.7(43.6)^{* * *}$ & 241.1 & $54.5(8.9)$ & $12.6(2.9)^{* * *}$ & -76.9 \\
\hline Phenylalanine & $50.5(9.0)$ & | $19 . \mid$ (50.9)**** & 235.8 & $49.1(6.9)$ & $7.4(1.9)^{* * *}$ & -84.9 \\
\hline Phe:LNAA & $0.104(0.04)$ & $0.069(0.02)^{*}$ & -33.7 & $0.10(0.03)$ & $0.004(0.002)^{* * *}$ & -96.0 \\
\hline
\end{tabular}

Abbreviations: APTD, acute phenylalanine tyrosine depletion; BAL, balanced; LNAA, large neutral amino acid; Phe, phenylalanine.

Biochemical data are presented as mean $\mu \mathrm{mol} / \mathrm{I}(\mathrm{SD})$.

$* p<0.001$.

*** $p<0.0001$. 
Table 3 Visual Analog Scores as a Function of Time and Cue Presentation

\begin{tabular}{|c|c|c|c|c|c|c|c|c|c|c|c|c|c|c|c|c|c|}
\hline \multicolumn{3}{|c|}{ Group } & \multicolumn{5}{|c|}{ HFSS } & \multicolumn{5}{|c|}{ LFSS } & \multicolumn{5}{|c|}{ LFES } \\
\hline $\begin{array}{l}\text { VAS } \\
\text { item }\end{array}$ & Effect & $\begin{array}{l}\text { AA } \\
\text { Mixture }\end{array}$ & Baseline & $t+4$ & Neu Cue & Cig Cue & Post-Cig & Baseline & $t+4$ & Neu Cue & Cig Cue & Post-Cig & Baseline & $t+4$ & Neu Cue & Cig Cue & Post-Cig \\
\hline \multirow[t]{2}{*}{ Euphoria } & $a, b b$ & BAL & $3.9(2.2)$ & $3.6(1.8)$ & $3.9(2.1)$ & $5.1(2.2)$ & $4.6(1.9)$ & $2.4(1.6)$ & $2.6(1.6)$ & $2.5(1.4)$ & $3.1(1.9)$ & $4.1(2.6)$ & $2.8(1.3)$ & $1.9(1.1)$ & $2.3(1.4)$ & $2.9(1.5)$ & $2.4(1.6)$ \\
\hline & & APTD & $3.3(1.1)$ & $2.6(1.4)$ & $3.3(1.8)$ & $4.2(2.3)$ & $3.9(2.2)$ & $2.4(1.1)$ & $2.0(0.8)$ & $2.3(1.3)$ & $2.7(1.5)$ & $4.4(2.4)$ & $2.1(1.1)$ & $1.9(1.1)$ & $2.0(1.2)$ & $2.3(1.1)$ & $2.8(1.6)$ \\
\hline \multirow[t]{2}{*}{ High } & $a, b b$ & BAL & $3.0(2.0)$ & $3.1(1.3)$ & $3.6(1.9)$ & $4.4(2.0)$ & $4.5(2.1)$ & $2.5(1.6)$ & $2.3(1.2)$ & $2.1(1.4)$ & $2.9(2.0)$ & $4.1(2.2)$ & $2.6(1.5)$ & $1.9(0.8)$ & $1.9(0.8)$ & $2.2(1.2)$ & $2.0(0.7)$ \\
\hline & & APTD & $2.2(1.3)$ & $2.3(1.3)$ & $2.8(1.5)$ & $3.4(1.7)$ & $4.3(2.6)$ & $2.2(1.1)$ & $2.5(1.6)$ & $2.2(1.1)$ & $2.8(1.5)$ & $4.7(2.1)$ & $1.8(0.8)$ & $1.6(0.5)$ & $1.4(0.5)$ & $1.8(1.0)$ & $2.4(1.7)$ \\
\hline \multirow[t]{2}{*}{ Like Cigarette } & $a, b b$ & BAL & $6.2(2.3)$ & $6.4(2.6)$ & $7.3(1.8)$ & $7.8(2.0)$ & $5.6(2.2)$ & $5.9(1.7)$ & $6.8(1.5)$ & $7.3(1.6)$ & $6.1(1.9)$ & $5.3(2.6)$ & $5.1(2.1)$ & $4.8(1.4)$ & $5.2(1.6)$ & $5.3(2.9)$ & $3.8(1.5)$ \\
\hline & & APTD & $5.7(2.5)$ & $6.5(1.8)$ & $6.4(2.6)$ & $7.3(2.2)$ & $5.4(2.8)$ & $5.5(3.5)$ & $6.1(3.2)$ & $6.0(3.2)$ & $6.8(2.5)$ & $5.8(2.0)$ & $4.2(1.9)$ & $4.6(1.7)$ & $4.3(2.1)$ & $5.3(1.9)$ & $4.7(2.2)$ \\
\hline \multirow[t]{2}{*}{ Want Cigarette } & $a, b b$ & BAL & $6.8(2.3)$ & $6.6(2.4)$ & $7.6(1.7)$ & $8.0(2.2)$ & $5.4(2.3)$ & $5.9(2.2)$ & $6.3(2.0)$ & $7.1(2.0)$ & $7.3(1.8)$ & $4.5(2.5)$ & $4.5(2.3)$ & $4.8(1.9)$ & $5.1(2.0)$ & $6.0(2.7)$ & $3.3(1.6)$ \\
\hline & & APTD & $5.7(2.8)$ & $6.7(2.2)$ & $6.8(2.4)$ & $7.5(2.5)$ & $5.0(3.0)$ & $5.9(3.7)$ & $6.4(3.4)$ & $7.0(2.7)$ & $6.4(3.3)$ & $5.0(2.4)$ & $3.9(2.0)$ & $4.5(2.1)$ & $4.5(1.5)$ & $5.5(2.1)$ & $3.9(1.7)$ \\
\hline
\end{tabular}

VAS data are presented as mean (SEM).

Results: 'a', Indicate group differences in ratings by HFSS compared with LFSS and LFES, $p<0.05$.

'bb', Refers to differences in ratings at Cig cue and Post-Cig time points across smoker groups, $p<0.01$.

Rating of VAS items 'Euphoria', 'High', 'Like Cigarette' and 'Want Cigarette' at five different time points following ingestion of a nutritionally balanced AA Mixture (BAL) compared with an AA Mixture deficient in phenylalanine and tyrosine depletion (APTD). HFSS, LFSS, and LFES refer to high-frequency stable smokers, low-frequency stable smokers and low-frequency early smokers, respectively. Neu Cue and Cig Cue refer to

Neutral Cue and Cigarette Cue. Values are reported as mean+SEM.

Table 4 Questionnaire of Smoking Urges Scores as a Function of Time and Cue Presentation

\begin{tabular}{|c|c|c|c|c|c|c|c|c|c|c|c|c|c|c|c|c|c|}
\hline \multirow{2}{*}{$\begin{array}{l}\text { AA } \\
\text { Mixture }\end{array}$} & \multirow{2}{*}{ Effect } & \multirow{2}{*}{ QSU } & \multicolumn{5}{|c|}{ HFSS } & \multicolumn{5}{|c|}{ LFSS } & \multicolumn{5}{|c|}{ LFES } \\
\hline & & & Baseline & $t+4$ & Neu Cue & Cig Cue & Post-Cig & Baseline & $t+4$ & Neu Cue & Cig Cue & Post-Cig & Baseline & $t+4$ & Cig Cue & Neu Cue & Post-Cig \\
\hline \multirow[t]{2}{*}{ BAL } & $b b$ & Factor I & $5.6(0.8)$ & $5.4(1.1)$ & $6.0(1.0)$ & $5.8(1.4)$ & $4.8(1.9)$ & $4.8(1.7)$ & $5.3(1.0)$ & $5.7(1.2)$ & $5.6(1.4)$ & $4.1(1.6)$ & $4.4(1.3)$ & $4.6(0.8)$ & $5.1(1.3)$ & $4.3(1.4)$ & $4.2(1.5)$ \\
\hline & $a, b$ & Factor 2 & $4.6(0.8)$ & $4.2(1.2)$ & $4.8(1.7)$ & $4.7(1.0)$ & $2.9(1.6)$ & $3.8(0.8)$ & $4.1(1.0)$ & $4.4(1.3)$ & $4.5(1.6)$ & $3.2(1.7)$ & $2.5(0.8)$ & $2.9(0.9)$ & $3.0(1.2)$ & $2.7(1.1)$ & $2.6(0.9)$ \\
\hline \multirow[t]{2}{*}{ APTD } & $b b$ & Factor I & $5.6(0.7)$ & $5.3(1.5)$ & $5.9(1.0)$ & $5.5(1.3)$ & $4.9(1.8)$ & $5.1(1.7)$ & $5.2(1.6)$ & $5.4(1.6)$ & $5.7(1.4)$ & $3.6(1.6)$ & $4.4(1.2)$ & $4.5(1.2)$ & $5.0(1.0)$ & $5.1(1.0)$ & $3.9(1.0)$ \\
\hline & $a, b$ & Factor 2 & $4.2(1.1)$ & $4.4(1.3)$ & $4.9(1.4)$ & $4.2(1.4)$ & $3.8(1.7)$ & $3.7(1.2)$ & $4.3(1.2)$ & $4.5(1.6)$ & $4.8(1.7)$ & $3.0(1.6)$ & $2.4(0.9)$ & $2.5(1.0)$ & $3.1(1.0)$ & $3.1(1.2)$ & $2.5(1.1)$ \\
\hline
\end{tabular}

Abbreviations: APTD, AA Mixture deficient in phenylalanine and tyrosine depletion; BAL, nutritionally balanced AA Mixture; Cig Cue, Cigarette Cue; HFSS, high-frequency stable smokers; LFES, low-frequency early smokers; LFSS, low-frequency stable smokers; Neu Cue, Neutral Cue; QSU, questionnaire of smoking urge.

QSU data are presented as mean (SEM).

Results: a, main effect of group, $p<0.01$

b, bb, Main effect of time, $p<0.01, p<0.05$, respectively.

QSU Factor I and Factor 2 scores at five different time points following ingestion of BAL compared with an APTD. Values are reported as mean+SEM. 'aa', Indicate differences in Factor 2 scores in HFSS and LFSS

compared with LFES, $p<0.01$. 'bb' Refers to differences in Factor I and Factor 2 scores at the Post-Cig time point across smoker groups, $p<0.01$. 


\section{Effect Of APTD On Self-Reported Mood}

Analyses did not reveal main effects of Group, AA Mixture, or of Time $(p>0.4)$ on BDI or POMS scores, or significant interactions $(p=0.58)$.

\section{DISCUSSION}

The present study provides the first investigation of the role of DA in low-frequency smokers. As seen previously in non-dependent users of other substances, reducing DA transmission decreased self-administration behavior (Barrett et al, 2008; Brauer et al, 2001; Enggasser and de Wit, 2001; Leyton et al, 2000a; although see Leyton et al (2005)). More importantly, the same reduction was seen in high-frequency, nicotine-dependent smokers. Together, these findings suggest that DA affects motivation to obtain drug reward across degrees of addiction, at least in the case of tobacco.

In previous research, APTD has been demonstrated to decrease striatal DA release induced by $d$-amphetamine (Leyton et al, 2004). In the present study, APTD likely decreased nicotine-induced DA release, an effect proposed to diminish the ability to sustain motivation to obtain multiple mini-cigarettes. More generally, the results add to the evidence that the motivation to seek drugs is promoted by increases in DA transmission rather than decreases (Stewart, 2008).

The measure of motivation to obtain cigarettes was the PR breakpoint (Roberts et al, 1989). Reductions in breakpoints could occur for multiple reasons, including decreases in craving or pleasurable effects related to reward. In the present study, PR breakpoints were reduced in the absence of changes to craving or pleasure. This observation is supported by growing evidence that mesolimbic DA transmission influences incentive salience but that this is not because of conscious processing or altered hedonic experience (Berridge and Robinson, 1998; Leyton, 2009). Consistent with this interpretation, neither APTD (Casey et al, 2006; Hitsman et al, 2008; Munafo et al, 2007) nor DA receptor antagonists (Brauer et al, 2001; Dawe et al, 1995; Mahler and de Wit, 2005) diminished self-reported craving or pleasure in previous studies conducted in dependent smokers.

As expected, HFSS worked for more nicotine-containing cigarettes than either group of low-frequency smokers. Unexpected, though, was that both groups of long-term smokers (LFSS, HFSS), regardless of smoking frequency, rated cigarette 'Liking', 'Wanting', and the negative aspects of craving (eg, negative mood, irritability) significantly higher than those who had been smoking for less than a year. These observations suggest that subjective symptoms of dependence can precede additional increases in smoking behavior (DiFranza et al, 2007; Gervais et al, 2006).

The observation that low- and high-frequency smokers all worked more for nicotine-containing cigarettes than denicotinized ones adds to a literature that has been surprisingly equivocal. Although smokers consistently prefer nicotine-containing cigarettes when given a choice (Barrett, 2010; Shahan et al, 1999), de-nicotinized cigarettes mimic the sensory properties of smoking (Donny and Jones, 2009), reduce smoking urges, elicit positive emotional states
(Barrett, 2010), and have been reported to maintain similar rates of self-administration as nicotine-containing cigarettes, as measured with a PR breakpoint task (Donny et al, 2007; Rusted et al, 1998; Shahan et al, 1999). The discrepancy between the results obtained in the present study and those reported previously is likely due to methodological differences. First, in those studies, smokers were minimally deprived of nicotine (less than $1 \mathrm{~h}$ ) (Rusted et al, 1998; Shahan et al, 1999), likely dampening their motivation to work for nicotine-containing puffs. In the present study, all smokers were nicotine abstinent for at least $12 \mathrm{~h}$. Second, in the previous studies the nicotinecontaining and de-nicotinized cigarettes were self-administered by separate groups of subjects, making conclusions about relative reinforcing efficacy difficult because individual subjects were not given a choice between the two cigarette types. Preference in a choice situation is generally a more sensitive measure of differences in reinforcer efficacy (Shahan et al, 1999).

The results of the present study should be interpreted in light of the following considerations. First, the sample sizes were modest ( $n=15-16$ per group); however, previous studies have demonstrated that 8 to 14 subjects are sufficient to see effects of APTD on PR self-administration breakpoints for alcohol and the ability to preferentially respond to reward-paired cues (Barrett et al, 2008; Leyton et al, 2007; Leyton et al, 2005). Although we might have missed group differences in the magnitude of this effect, all three groups exhibited a $20-25 \%$ decrease in PR breakpoints, and the Group $\times$ AA Mixture interaction effects were far from the trend level, $\alpha=0.59$ and 0.43 . Second, in previous studies that tested the effect of decreasing DA transmission on cigarette self-administration in dependent smokers, the effects have been inconsistent, possibly reflecting differences between ad lib self-administration regimens $v s$ PR breakpoints, length of nicotine abstinence, or other methodological differences. Third, we did not measure plasma levels of nicotine or cotinine. This noted, previous studies indicate that low- and high-frequency smokers do not differ in smoking topography, nicotine metabolism, or blood nicotine levels following smoking (Arcavi et al, 1994; Shiffman et al, 1992). In comparison, the primary focus of the present study was whether lowering DA synthesis would alter the motivation to obtain cigarettes. Notably, APTD does not alter the inhalation topography of smoking puffs (Casey et al, 2006). Finally, we recruited smokers aged $18-25$ years, university educated, of normal weight, and without significant mental health issues. We selected this population to ensure that the LFSS and HFSS groups would be similar in terms of the number of years smoking and to avoid demographic confounds. Nevertheless, we were able to detect group differences in PR responding and self-reported craving, indicating that the experimental design could capture the targeted differences.

In summary, two main novel findings were obtained in this study. First, APTD diminished the willingness to work for nicotine-containing cigarettes without changing selfreported craving or pleasure. This suggests that the motivation to smoke $v s$ conscious craving and pleasure might be mediated by distinct neurochemical systems, with DA having greater importance for the first. Second, motivation 
to earn cigarettes remained DA-sensitive across varying levels of addiction as the magnitude of APTD's effect was the same in all three smoking groups. Although smoking might induce long-lasting changes to the DA system, such as tolerance or sensitization, our results suggest that the motivational drive to obtain nicotine-containing cigarettes remains under the transmitter's influence.

\section{ACKNOWLEDGEMENTS}

We thank Franceen Lenoff and Kathleen Auclair for their excellent technical assistance.

\section{DISCLOSURE}

This work was funded by operating grants from CTCRI (017754) and CIHR (79919) to ML, and from NIH/NIDA (SNS-82249) and CIHR (DA022630 \& RAN-79911) to LKF. JOL holds a Canada Research Chair in the Early Determinants of Adult Chronic Disease. KFC was the recipient of a scholarship from Fonds de la recherche en santé du Québec. $\mathrm{CB}$ and ML hold research chairs at McGill University. During the past 3 years, ML has received research funds from GSK for research unrelated to the present study. The remaining authors declare no conflict of interest.

\section{REFERENCES}

Arcavi L, Jacob 3rd P, Hellerstein M, Benowitz NL (1994). Divergent tolerance to metabolic and cardiovascular effects of nicotine in smokers with low and high levels of cigarette consumption. Clin Pharmacol Ther 56: 55-64.

Balfour DJ, Benwell ME, Birrell CE, Kelly RJ, Al-Aloul M (1998). Sensitization of the mesoaccumbens dopamine response to nicotine. Pharmacol Biochem Behav 59: 1021-1030.

Barrett SP (2010). The effects of nicotine, denicotinized tobacco, and nicotine-containing tobacco on cigarette craving, withdrawal, and self-administration in male and female smokers. Behav Pharmacol 21: 144-152.

Barrett SP, Boileau I, Okker J, Pihl RO, Dagher A (2004). The hedonic response to cigarette smoking is proportional to dopamine release in the human striatum as measured by positron emission tomography and [11C]raclopride. Synapse 54: 65-71.

Barrett SP, Pihl RO, Benkelfat C, Brunelle C, Young SN, Leyton M (2008). The role of dopamine in alcohol self-administration in humans: individual differences. Eur Neuropsychopharmacol 18: 439-447.

Barrett SP, Tichauer M, Leyton M, Pihl RO (2006). Nicotine increases alcohol self-administration in non-dependent male smokers. Drug Alcohol Depend 81: 197-204.

Beck AT (1961). A systematic investigation of depression. Compr Psychiatry 2: 163-170.

Benwell ME, Balfour DJ (1992). The effects of acute and repeated nicotine treatment on nucleus accumbens dopamine and locomotor activity. Br J Pharmacol 105: 849-856.

Berridge KC, Robinson TE (1998). What is the role of dopamine in reward: hedonic impact, reward learning, or incentive salience? Brain Res Brain Res Rev 28: 309-369.

Brauer LH, Cramblett MJ, Paxton DA, Rose JE (2001). Haloperidol reduces smoking of both nicotine-containing and denicotinized cigarettes. Psychopharmacology (Berl) 159: 31-37.

Brauer LH, Hatsukami D, Hanson K, Shiffman S (1996). Smoking topography in tobacco chippers and dependent smokers. Addict Behav 21: 233-238.
Brody AL (2006). Functional brain imaging of tobacco use and dependence. J Psychiatr Res 40: 404-418.

Brody AL, Olmstead RE, London ED, Farahi J, Meyer JH, Grossman P et al. (2004). Smoking-induced ventral striatum dopamine release. Am J Psychiatry 161: 1211-1218.

Casey KF, Benkelfat C, Young SN, Leyton M (2006). Lack of effect of acute dopamine precursor depletion in nicotine-dependent smokers. Eur Neuropsychopharmacol 16: 512-520.

Caskey NH, Jarvik ME, Wirshing WC (1999). The effects of dopaminergic D2 stimulation and blockade on smoking behavior. Exp Clin Psychopharmacol 7: 72-78.

Caskey NH, Jarvik ME, Wirshing WC, Madsen DC, IwamotoSchaap PN, Eisenberger NI et al. (2002). Modulating tobacco smoking rates by dopaminergic stimulation and blockade. Nicotine Tob Res 4: 259-266.

Clarke PB (1990). Mesolimbic dopamine activation-the key to nicotine reinforcement? Ciba Found Symp 152: 153-162 discussion 162-168.

Clarke PB, Fu DS, Jakubovic A, Fibiger HC (1988). Evidence that mesolimbic dopaminergic activation underlies the locomotor stimulant action of nicotine in rats. J Pharmacol Exp Ther 246: 701-708.

Clarke PB, Kumar R (1983). The effects of nicotine on locomotor activity in non-tolerant and tolerant rats. Br J Pharmacol 78: 329-337.

Corrigall WA, Coen KM (1991). Selective dopamine antagonists reduce nicotine self-administration. Psychopharmacology (Berl) 104: $171-176$

Dawe S, Gerada C, Russell MA, Gray JA (1995). Nicotine intake in smokers increases following a single dose of haloperidol. Psychopharmacology (Berl) 117: 110-115.

Di Chiara G, Imperato A (1988). Drugs abused by humans preferentially increase synaptic dopamine concentrations in the mesolimbic system of freely moving rats. Proc Natl Acad Sci USA 85: 5274-5278.

DiFranza JR, Savageau JA, Fletcher K, O’Loughlin J, Pbert L, Ockene JK et al. (2007). Symptoms of tobacco dependence after brief intermittent use: the Development and Assessment of Nicotine Dependence in Youth-2 study. Arch Pediatr Adolesc Med 161: 704-710.

DiFranza JR, Savageau JA, Fletcher K, Ockene JK, Rigotti NA, McNeill $\mathrm{AD}$ et al. (2002). Measuring the loss of autonomy over nicotine use in adolescents: the DANDY (Development and Assessment of Nicotine Dependence in Youths) study. Arch Pediatr Adolesc Med 156: 397-403.

Domino EF, Tsukada H (2009). Nicotine sensitization of monkey striatal dopamine release. Eur J Pharmacol 607: 91-95.

Donny EC, Houtsmuller E, Stitzer ML (2007). Smoking in the absence of nicotine: behavioral, subjective and physiological effects over 11 days. Addiction 102: 324-334.

Donny EC, Jones M (2009). Prolonged exposure to denicotinized cigarettes with or without transdermal nicotine. Drug Alcohol Depend 104: 23-33.

Enggasser JL, de Wit H (2001). Haloperidol reduces stimulant and reinforcing effects of ethanol in social drinkers. Alcohol Clin Exp Res 25: 1448-1456.

Fagerstrom KO (1978). Measuring degree of physical dependence to tobacco smoking with reference to individualization of treatment. Addict Behav 3: 235-241.

Fagerstrom KO, Schneider NG (1989). Measuring nicotine dependence: a review of the Fagerstrom Tolerance Questionnaire. J Behav Med 12: 159-182.

First MB (1995). Structured Clinical Interview For DSM-IV Axis I Disorders. New York State Psychiatric Institute: New York.

Gervais A, O’Loughlin J, Meshefedjian G, Bancej C, Tremblay M (2006). Milestones in the natural course of onset of cigarette use among adolescents. CMAJ 175: 255-261. 
Heatherton TF, Kozlowski LT, Frecker RC, Fagerstrom KO (1991). The Fagerstrom test for nicotine dependence: a revision of the Fagerstrom Tolerance Questionnaire. Br J Addict 86: 1119-1127.

Hitsman B, MacKillop J, Lingford-Hughes A, Williams TM, Ahmad F, Adams S et al. (2008). Effects of acute tyrosine/phenylalanine depletion on the selective processing of smoking-related cues and the relative value of cigarettes in smokers. Psychopharmacology (Berl) 196: 611-621.

Hutchison KE, Rutter MC, Niaura R, Swift RM, Pickworth WB, Sobik L (2004). Olanzapine attenuates cue-elicited craving for tobacco. Psychopharmacology (Berl) 175: 407-413.

Leyton M (2009). The neurobiology of desire: dopamine and the regulation of mood and motivational states in humans. in: Kringelbach ML, Berridge K.(eds) Pleasures of the Brain. Oxford University Press: New York. Ch.13.

Leyton $M$, aan het Rot $M$, Booij L, Baker GB, Young SN, Benkelfat C (2007). Mood-elevating effects of d-amphetamine and incentive salience: the effect of acute dopamine precursor depletion. J Psychiatry Neurosci 32: 129-136.

Leyton M, Casey KF, Delaney JS, Kolivakis T, Benkelfat C (2005). Cocaine craving, euphoria, and self-administration: a preliminary study of the effect of catecholamine precursor depletion. Behav Neurosci 119: 1619-1627.

Leyton M, Dagher A, Boileau I, Casey K, Baker GB, Diksic M et al. (2004). Decreasing amphetamine-induced dopamine release by acute phenylalanine/tyrosine depletion: A PET/[11C]raclopride study in healthy men. Neuropsychopharmacology 29: 427-432.

Leyton M, Young SN, Blier P, Baker GB, Pihl RO, Benkelfat C (2000a). Acute tyrosine depletion and alcohol ingestion in healthy women. Alcohol Clin Exp Res 24: 459-464.

Leyton M, Young SN, Pihl RO, Etezadi S, Lauze C, Blier P et al. (2000b). Effects on mood of acute phenylalanine/tyrosine depletion in healthy women. Neuropsychopharmacology 22: 52-63.

Liu X, Jernigen C, Gharib M, Booth S, Caggiula AR, Sved AF (2010). Effects of dopamine antagonists on drug cue-induced reinstatement of nicotine-seeking behavior in rats. Behav Pharmacol 21: 153-160.

Lorr M, McNair DM, Fisher SU (1982). Evidence for bipolar mood states. J Pers Assess 46: 432-436.

Louis M, Clarke PB (1998). Effect of ventral tegmental 6-hydroxydopamine lesions on the locomotor stimulant action of nicotine in rats. Neuropharmacology 37: 1503-1513.

Mahler SV, de Wit H (2005). Effects of haloperidol on reactions to smoking cues in humans. Behav Pharmacol 16: 123-126.

Munafo MR, Mannie ZN, Cowen PJ, Harmer CJ, McTavish SB (2007). Effects of acute tyrosine depletion on subjective craving and selective processing of smoking-related cues in abstinent cigarette smokers. J Psychopharmacol 21: 805-814.

Roberts DC, Loh EA, Vickers G (1989). Self-administration of cocaine on a progressive ratio schedule in rats: dose-response relationship and effect of haloperidol pretreatment. Psychopharmacology (Berl) 97: 535-538.

Rose JE, Corrigall WA (1997). Nicotine self-administration in animals and humans: similarities and differences. Psychopharmacology (Berl) 130: 28-40.

Rusted JM, Mackee A, Williams R, Willner P (1998). Deprivation state but not nicotine content of the cigarette affects responding by smokers on a progressive ratio task. Psychopharmacology (Berl) 140: 411-417.

Scott DJ, Domino EF, Heitzeg MM, Koeppe RA, Ni L, Guthrie S et al. (2007). Smoking modulation of mu-opioid and dopamine D2 receptor-mediated neurotransmission in humans. Neuropsychopharmacology 32: 450-457.

Shahan TA, Bickel WK, Madden GJ, Badger GJ (1999). Comparing the reinforcing efficacy of nicotine containing and de-nicotinized cigarettes: a behavioral economic analysis. Psychopharmacology (Berl) 147: 210-216.

Shiffman S, Zettler-Segal M, Kassel J, Paty J, Benowitz NL, O'Brien G (1992). Nicotine elimination and tolerance in non-dependent cigarette smokers. Psychopharmacology (Berl) 109: 449-456.

Shim I, Javaid JI, Wirtshafter D, Jang SY, Shin KH, Lee HJ et al. (2001). Nicotine-induced behavioral sensitization is associated with extracellular dopamine release and expression of c-Fos in the striatum and nucleus accumbens of the rat. Behav Brain Res 121: 137-147.

Shoaib M, Benwell ME, Akbar MT, Stolerman IP, Balfour DJ (1994). Behavioural and neurochemical adaptations to nicotine in rats: influence of NMDA antagonists. $\mathrm{Br} J$ Pharmacol 111: 1073-1080.

Shoaib M, Schindler CW, Goldberg SR (1997). Nicotine self-administration in rats: strain and nicotine pre-exposure effects on acquisition. Psychopharmacology (Berl) 129: 35-43.

Sorge RE, Clarke PB (2009). Rats self-administer intravenous nicotine delivered in a novel smoking-relevant procedure: effects of dopamine antagonists. J Pharmacol Exp Ther 330: 633-640.

Spina L, Fenu S, Longoni R, Rivas E, Di Chiara G (2006). Nicotineconditioned single-trial place preference: selective role of nucleus accumbens shell dopamine D1 receptors in acquisition. Psychopharmacology (Berl) 184: 447-455.

Stewart J (2008). Review. Psychological and neural mechanisms of relapse. Philos Trans R Soc Lond B Biol Sci 363: 3147-3158.

Tang J, Dani JA (2009). Dopamine enables in vivo synaptic plasticity associated with the addictive drug nicotine. Neuron 63: 673-682.

Tiffany ST, Drobes DJ (1991). The development and initial validation of a questionnaire on smoking urges. $\mathrm{Br} J$ Addict 86: 1467-1476.

Vezina P, McGehee DS, Green WN (2007). Exposure to nicotine and sensitization of nicotine-induced behaviors. Prog Neuropsychopharmacol Biol Psychiatry 31: 1625-1638.

Supplementary Information accompanies the paper on the Neuropsychopharmacology website (http://www.nature.com/npp) 